\title{
Phylogeny of ambro beetle symbionts in the genus Raffaelea
}

Tyler J. Dreaden ${ }^{\mathrm{a}}$, John M. Davis ${ }^{\mathrm{a}}$, Z. Wilhelm de Beer ${ }^{\mathrm{b}}$, Randy C. Ploetz ${ }^{\mathrm{c}}$, Pamela S. Soltis ${ }^{d}$, Michael J. Wingfield ${ }^{b}$, Jason A. Smith ${ }^{a^{*}}$

${ }^{a}$ School of Forest Resources and Conservation, University of Florida, Gainesville 32611, United States of America

${ }^{b}$ Department of Microbiology and Plant Pathology, Forestry and Agricultural Biotechnology Institute (FABI), University of Pretoria, Pretoria, 0002, South Africa

${ }^{\mathrm{C}}$ Tropical Research and Education Center, University of Florida, Homestead 33031, United States of America

${ }^{d}$ Florida Museum of Natural History, University of Florida, Gainesville 32611, United States of America * Corresponding author. School of Forest Resources and Conservation, PO Box 110410, University of Florida, Gainesville, FL 32611-0410, USA, Tel.: +1 352846 0843. E-mail address: jasons@ufl.edu

\section{Abstract}

The genus Raffaelea was established in 1965 when the type species, $R$. ambrosia, a symbiont of Platypus ambrosia beetles was described. Since then, many additional ambrosia beetle symbionts have been added to the genus, including the important tree pathogens $R$. quercivora, $R$. quercus-mongolicae, and $R$. lauricola, causal agents of Japanese and Korean oak wilt and laurel wilt, respectively. The discovery of new and the dispersal of described species of Raffaelea to new areas, where they can become invasive, presents challenges for diagnosticians as well as plant protection and quarantine efforts. In this paper, we present the first comprehensive multigene phylogenetic analysis of Raffaelea. As it is currently defined, the genus was found to not be monophyletic. On the basis of this work, Raffaelea sensu stricto is defined and the affinities of undescribed isolates are considered.

\section{Keywords}

Raffaelea sensu stricto; Ophiostomatales; internal transcribed spacer region; ITS; ambrosia fungi; wilt pathogens 


\section{Research highlights}

- Raffaelea as it is currently defined is not monophyletic.

- Raffaelea sensu stricto is defined.

- Raffaelea spp. isolates with unclear affinities are identified.

\section{Introduction}

Both Raffaelea and Ambrosiella species colonize the natal galleries of ambrosia beetles in tree sapwood, and they maintain close associations with these insects (Batra 1967). Although most Raffaelea spp. live as saprophytes, colonizing dead and dying wood, some species such as $R$. lauricola, $R$. quercivora, and $R$. quercus-mongolicae are serious pathogens that can cause significant damage to forests and fruit crops (Kim et al. 2009, Kubono and Ito 2002, Ploetz et al. 2013). The causal agent of laurel wilt, $R$. lauricola, is highly virulent and able to cause systemic wilt from a single inoculation. It threatens native Lauraceae in the southeastern United States and avocado production in Florida (Ploetz et al. 2011, Ploetz et al. 2013). Thus, the discovery of new taxa and the dispersal of known taxa to new areas may represent important threats to forests and agriculture. Clarification of the taxonomy of Raffaelea, and related genera, would clearly aid researchers and diagnosticians who deal with these important challenges. Additionally, clear taxonomy and a strong phylogeny of the genus would allow for an examination of the evolutionary biology of the ambrosial symbioses.

The genus Raffaelea was established by Arx and Hennebert (1965) to accommodate R. ambrosiae, a symbiont of Platypus ambrosia beetles; it currently includes up to 20 described species (Harrington et al. 2010; De Beer et al. 2013b). Raffaelea has traditionally been distinguished from Ambrosiella by the sympodial proliferation of the conidiogenous cells in Raffaelea and percurrent proliferation of the 
conidiogenous cells in Ambrosiella (Batra 1967, Harrington et al. 2008). This distinction is difficult to discern microscopically, and its utility to distinguish the two genera has been questioned (Gebhardt and Oberwinkler 2005, Harrington et al. 2008). Molecular phylogenetic approaches have been used to clarify the taxonomic relationships of most groups of fungi, including the Ophiostomatales (Duong et al. 2012, Farrell et al. 2001, James et al. 2006, Slippers et al. 2013, Wingfield et al. 2013). Ribosomal DNA sequence data have confirmed that the two genera are not closely related, as Raffaelea resides in the Ophiostomatales and Ambrosiella in the Microascales (Cassar \& Blackwell 1996; Jones \& Blackwell 1998; De Beer et al. 2013a).

The relationships between Raffaelea and related genera and their placement within the Ophiostomatales have not been fully resolved. The genus name Dryadomyces was introduced by Gebhardt et al. (2005) to accommodate D. amasae (=R. amasae). It fell in the Raffaelea clade in their phylogenetic analyses of the rDNA small ribosomal subunit (SSU) sequences, but based on conidiogenesis, it differed from Raffaelea. Harrington et al. (2008) reduced Dryadomyces to synonymy with Raffaelea, supporting the view that all ambrosia beetle symbionts with similarities to Ophiostoma should be included in Raffaelea. Massoumi Alamouti et al. (2009) conducted a multigene phylogenetic analysis of a limited sampling of ambrosia fungi. They showed that $D$. amasae grouped in a monophyletic lineage distinct from the lineage containing R. ambrosiae, the type species for Raffaelea. However, Harrington et al. (2010) revised Raffaelea and maintained the synonymy of Dryadomyces with Raffaelea. In a taxonomic review of the Ophiostomatales, De Beer \& Wingfield (2013) contextualized the phylogenetic placement of Raffaelea spp. alongside all other accepted genera within 
the order based on available LSU data, confirming the polyphyly of the genus as suggested by Massoumi Alamouti et al. (2009). They defined Raffaelea sensu stricto, as well as two distinct clades. In one clade, $R$. lauricola, $R$. brunnea, and an undescribed species from Canada were included in Ophiostoma sensu lato, but the definition of what should be included in Ophiostoma was vague. The second clade included $R$. quercivora, $R$. montetyi, $R$. sulphurea, and $R$. amasae in Leptographium sensu lato (De Beer \& Wingfield 2013). These authors concluded that additional data would be required to fully resolve the generic status of these two unrelated clades accommodating diverse species of Raffaelea.

The objectives of this study were to conduct multigene phylogenetic analyses of Raffaelea spp. and to test the monophyly of the genus as it is currently defined. An additional objective was to assess the affinity of a collection of isolates that have yet to be identified.

\section{Materials and Methods}

\subsection{Taxon Sampling}

Data from previous studies were assessed and the LSU, SSU, and $\beta$-tubulin (BT) loci were selected for the present study because they have been useful for constructing phylogenies for these fungi and are available in GenBank (Massoumi Alamouti et al. 2009, Harrington et al. 2010, De Beer \& Wingfield 2013). In all, 77 isolates were analyzed, including 9 in the Microascales and 55 in the Ophiostomatales (18 species of Ophiostoma, three of Ceratocystiopsis, 11 of Grosmannia, one of Esteya, two of Fragosphaeria, and all 20 species of Raffaelea that were defined by Harrington et al. (2010)) (Table 1). Unidentified isolates and outgroup taxa comprised the remaining 
isolates. Sequences were either acquired from GenBank or obtained by sequencing

\section{(Table 1).}

Table 1. Taxon names, isolate and GenBank accession numbers used in the study.

\begin{tabular}{|c|c|c|c|}
\hline \multirow{2}{*}{ Taxon Isolate } & \multicolumn{3}{|c|}{ Accession } \\
\hline & LSU & SSU & BT \\
\hline Ambrosiella ferruginea CBS408.68 & EU984285 & EU984254 & EU977461 \\
\hline Ambrosiella ferruginea JB13 & EU984286 & EU984255 & EU977462 \\
\hline Ambrosiella hartigii CBS404.82 & EU984288 & EU984256 & EU977463 \\
\hline Ambrosiella xylebori CBS110.61 & EU984294 & AY858659 & EU977469 \\
\hline Ceratocystiopsis manitobensis UM237 & DQ268607 & EU984266 & DQ268638 \\
\hline Ceratocystiopsis minuta CBS463.77 & DQ268615 & EU984267 & EU977481 \\
\hline Ceratocystiopsis minuta-bicolor CBS635.66 & DQ268616 & EU984268 & EU977482 \\
\hline Ceratocystis adiposa CBS600.74 & EU984304 & EU984263 & EU977479 \\
\hline Ceratocystis coerulescens CL13-12 & AY214000 & EU984264 & AY140945 \\
\hline Ceratocystis moniliformis CBS155.62 & EU984305 & EU984265 & EU977480 \\
\hline Claviceps fusiformis ATCC26019 & U17402 & DQ522539 & AF263569 \\
\hline Daldinia concentrica & U47828 & U32402 & FJ185285 \\
\hline Epichloe typhina & U17396 & AB105953 & X52616 \\
\hline Esteya vermicola CBS115803 & EU668903 & & FJ490552 \\
\hline Fragosphaeria purpurea CBS133.34 & AF096191 & AF096176 & \\
\hline Fragosphaeria reniformis CBS134.34 & AB189155 & AB278193 & \\
\hline Grosmannia abiocarpa MUCL18351 & AJ538339 & EU984269 & DQ097857 \\
\hline Grosmannia clavigera ATCC18086 & AY544613 & EU984270 & AY263194 \\
\hline Grosmannia cucullata & AJ538335 & AY497513 & EU977483 \\
\hline Grosmannia penicillata & DQ097851 & AY858662 & DQ097861 \\
\hline Grosmannia piceiperda & AY707209 & AY497514 & AY707195 \\
\hline Grosmannia serpens & DQ294394 & AY497516 & AY707188 \\
\hline Leptographium abietinum DAOM60343 & DQ097852 & EU984271 & AY263182 \\
\hline Leptographium fruticetum DAOM234390 & DQ097848 & EU984272 & DQ097855 \\
\hline Leptographium longiclavatum & AY816686 & EU984273 & AY288934 \\
\hline Leptographium lundbergii UAMH9584 & AY544603 & EU984274 & AY263184 \\
\hline Leptographium terebrantis UAMH9722 & AY544606 & EU984275 & AY263192 \\
\hline Microascus cirrosus CBS217.31 & AF275539 & EU984279 & EU977490 \\
\hline Ophiostoma abietinum & AF155685 & EU984276 & EU977484 \\
\hline Ophiostoma bicolor & DQ268604 & AY497512 & DQ268635 \\
\hline Ophiostoma canum & AJ538342 & EU984277 & EU977485 \\
\hline Ophiostoma floccosum & AJ538343 & AF139810 & AY789142 \\
\hline Ophiostoma ips & AY172022 & AY172021 & GU170412 \\
\hline Ophiostoma macrosporum CBS367.53 & EU984290 & EU984257 & EU977465 \\
\hline Ophiostoma montium CBS15178 & AY194947 & EU984278 & AY194963 \\
\hline
\end{tabular}




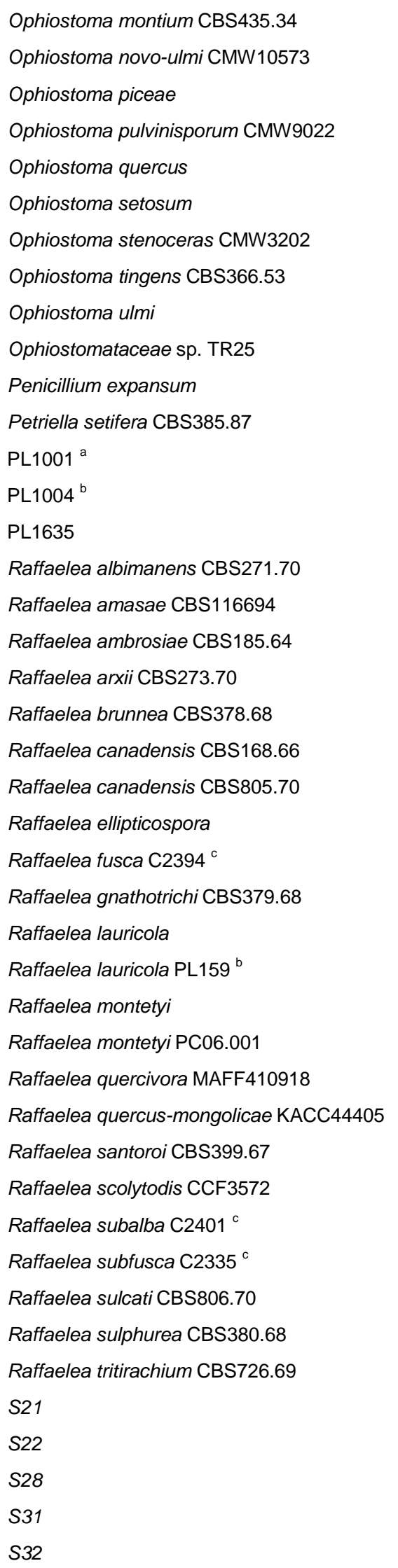

\begin{tabular}{|c|c|c|}
\hline EU984289 & AY858657 & EU977464 \\
\hline DQ294375 & & FJ430508 \\
\hline AJ538341 & AB007663 & AY305698 \\
\hline DQ294380 & & EU977487 \\
\hline DQ294376 & AF234835 & AY789157 \\
\hline AF128929 & & AY305703 \\
\hline DQ294350 & FJ176850 & DQ296074 \\
\hline EU984293 & EU984258 & EU977468 \\
\hline DQ368627 & M83261 & EU977489 \\
\hline EU984281 & EU984251 & EU977457 \\
\hline U15483 & DQ912698 & AF003248 \\
\hline AF027666 & EU984280 & EU977491 \\
\hline KJ909293 ${ }^{d}$ & KJ909294 & KJ909295 ${ }^{d}$ \\
\hline KJ909296 ${ }^{d}$ & KF026302 & KJ909297 ${ }^{d}$ \\
\hline KJ909308 & KJ909309 & KJ909310 \\
\hline EU984296 & EU984259 & EU977471 \\
\hline EU984295 & AY858660 & EU977470 \\
\hline EU984297 & AY497518 & EU977472 \\
\hline EU984298 & AY497519 & \\
\hline EU984284 & AY858654 & EU977460 \\
\hline EU984299 & AY858665 & EU977473 \\
\hline EU984291 & AY858658 & EU977466 \\
\hline HQ688664 & KJ909299 cd & KJ909298 ${ }^{\text {cd }}$ \\
\hline EU177449 & KJ909300 d & $\mathrm{KJ} 909301^{\mathrm{d}}$ \\
\hline EU177460 & AY858655 & \\
\hline EU123077 & EU123076 & \\
\hline KJ909303 ${ }^{d}$ & EU257806 & KJ909302 ${ }^{d}$ \\
\hline EU984301 & AY497520 & EU977475 \\
\hline JF909540 & JF909512 & \\
\hline \multirow[t]{2}{*}{ AB496454 } & AB496428 & GQ225691 \\
\hline & GQ225700 & GQ225688 \\
\hline EU984302 & EU984261 & EU977476 \\
\hline AM267270 & AM267261 & \\
\hline EU177443 & KJ909304 ${ }^{d}$ & KJ909305 \\
\hline EU177450 & KJ909306 ${ }^{d}$ & KJ909307 \\
\hline EU177462 & AY858666 & EU977477 \\
\hline EU984292 & EU170272 & EU977467 \\
\hline \multirow[t]{6}{*}{ EU984303 } & EU984262 & EU977478 \\
\hline & KJ909314 & \\
\hline & KJ909311 & \\
\hline & KJ909312 & \\
\hline & KJ909313 & \\
\hline & KJ909315 & \\
\hline
\end{tabular}


Sporothrix humicola CMW7618

Sporothrix schenckii

Sporothrix schenckii CMW7614

Taphrina populina CBS337.55

Xylaria sp.

${ }^{a}$ isolate UCR1073 from Eskalen and McDonald (2011), ${ }^{b}$ from authors collections,

${ }^{c}$ from Dr. T. C. Harrington lowa State University, ${ }^{d}$ Sequenced in this study,
EF139114

DQ294353

DQ294352

AF492050

AY327481
EF139100

DQ296076

AY280477

AF170968

AY951763

\subsection{DNA Extraction, PCR Amplification, and Sequencing}

Polymerase chain reactions were performed using DNA that was extracted from cultures (Justesen et al. 2002, Duong et al. 2012) using PCR primer pairs NL1/LR3, NS1/NS4, and Bt2a/Bt2b for the LSU, SSU, and BT loci, respectively (Glass and Donaldson 1995, O'Donnell 1993, Vilgalys and Hester 1990, White et al. 1990). Sanger sequencing was performed using the same primers at the University of Florida Interdisciplinary Center for Biotechnology Research, and consensus sequences were constructed using both the forward and reverse sequence reads using Geneious Pro 5.6.6 (Biomatters Ltd., Auckland, New Zealand). After many attempts, rDNA internal transcribed spacer region ITS1-5.8s-ITS2 (ITS) PCR amplicons were generated for several Raffaelea spp. isolates using FastStart Taq with the GC-RICH solution (Roche Applied Science, Basel, Switzerland) and primers ITS1F/ITS4 (Gardes and Bruns 1993, White et al. 1990). Sanger sequencing of ITS amplicons was performed at the Forestry and Agricultural Biotechnology Institute (FABI), University of Pretoria, Pretoria, South Africa, and aligned as above.

\subsection{Phylogenetic Analyses}

DNA sequences were aligned with sequences retrieved from GenBank (Table 1) using the Geneious alignment default settings in Geneious Pro 5.6.6, manually adjusted, and then trimmed. The introns in the BT loci could not be unambiguously 
aligned and were removed from the dataset. The presence or absence of the BT introns was also coded, but gave maximum parsimony (MP) results similar to the nonintron-coded dataset and was not used in subsequent analyses. Congruence among the three datasets was first evaluated using the partition-homogeneity test (PHT) in $\mathrm{PAUP}^{*}$ 4.0a1, with a heuristic search, tree-bisection-reconnection (TBR) branch swapping algorithm and Maxtree set to auto increase, and again using Maxtree $=500$ with both TBR and nearest-neighbor interchange (NNI) branch swapping algorithms (Swofford 2003). Congruence among gene trees was evaluated by conducting a maximum likelihood (ML) analysis on each gene (Fig S2-S4), and then comparing the results visually. The ML analyses were conducted at the University of Florida High Performance Computing Center (HPC) using RAxML version 7.3.5 using the GTRGAMMAI model, as determined by JModelTest, with 100 distinct starting trees and 1000 bootstrap analyses (BS) (Posada 2008, Stamatakis 2006). Gene sequences (LSU, SSU, BT) missing from isolates were treated as missing data then concatenated to form the combined data set with 1849 characters total. The combined data set was analyzed using ML, as described above, with each gene in a separate partition.

The MP analysis was conducted using PAUP* 4.0a129 with gaps treated as missing data, a heuristic search with 10 random stepwise addition replicates, and TBR (Swofford 2003). Branches with zero branch lengths were collapsed, and support was assessed by BS analysis using 1000 MP heuristic searches using TBR. The Bayesian Inference $(\mathrm{BI})$ analysis was conducted at the HPC using MrBayes 3.2.1 using the GTR+I+G model with all parameters unlinked (adapted from JModelTest), each gene in a separate character set, and 5 million generations that were sampled every 1000 
generations (Ronquist et al. 2012). The first 5,000 trees were discarded as burn-in, as determined using Tracer 1.4, and the remaining 15,002 trees were used to calculate the posterior probabilities (PP) and construct the majority-rule consensus tree using MrBayes (Rambaut and Drummond 2007).

To test for monophyly of Raffaelea, Bayes factors (BF) were calculated by first conducting a $\mathrm{BI}$ analysis, as described above, with the addition of a constraint that the Raffaelea taxa form a single clade. BFs were then calculated using the harmonic mean from MrBayes and the BF from Tracer (Kass and Raftery 1995, Rambaut and Drummond 2007, Ronquist et al. 2012). Expected likelihood weight (ELW) and Shimodaira-Hasegawa (SH) tests were conducted in RAxML, as described above, with the addition of a monophyletic Raffaelea constraint tree (Stamatakis 2006).

An additional $\mathrm{ML}$ analysis was performed to determine the placement of undescribed isolates. To do this, sequences from seven isolates were included in the concatenated dataset: five (S21, S22, S28, S31, S32) from nutmeg, Myristica fragrans, with wilt symptoms in Grenada, one (PL1001, strain UCR 1073 GenBank Accession JF327799 from Eskalen and McDonald (2011) from avocado with wilt symptoms in California), and one (PL1635) associated with a pine-specific ambrosia beetle in Thailand. Only SSU sequences were available for the five isolates from Grenada, whereas SSU, LSU, and BT sequences were available for the remaining undescribed isolates. DNA sequence alignments and phylogenetic trees were deposited in TreeBase (http://purl.org/phylo/treebase/phylows/study/TB2:S15908).

\section{Results}

After running for two hours, the first PHT, with Maxtree set to auto increase, was still on replicate $1 \mathrm{a}$ and had 500,532 , and increasing, trees remaining to swap and was 
aborted. The inability of the PHT to reach completion was not surprising because the MP analysis of the LSU dataset resulted in 20,700 equally parsimonious trees (Fig S5). The next PHT analyses using Maxtree $=500$, yielded $\mathrm{P}$ values of 0.01 and $0.073($ TBR with 100 replicates, and NNI with 1000 replicates, respectively). Results from the PHT indicate the genes might be incongruent but are questionable because of the limited search strategies that were employed so the analysis could be completed effectively. For these reasons and other shortcomings of the PHT, as noted by Hipp et al. (2004) and references therein, we believe the PHT results do not provide sufficient evidence not to combine the datasets. The ML analyses of the individual genes showed weak support for both deeper nodes and terminal branches but the general topologies were similar (Fig S2-S4). The most notable differences were the placements of Ceratocystiopsis and Fragosphaeria, which probably contributed to the incongruent PHT. However, following similar conclusions by Massoumi Alamouti et al. (2009), we accepted that the gene histories were sufficiently similar to combine the data and we present results from both the combined and individual datasets (Fig 1, 2, S2-S4).

Taxa in the Ophiostomatales formed a highly supported clade with 100, 1, and 99 ML BS, BI PP, and MP BS values, respectively. All three analyses strongly supported placement of Ceratocystiopsis and Fragosphaeria in the Ophiostomatales; however, they could not be placed relative to the other genera because the individual gene phylogenies had different topologies (Fig 1, S2-S4). The Ophiostoma sensu lato clade was well supported with 88,1 , and 77 ML BS, BI PP, and MP BS values, respectively. Raffaelea fell into two clades, one of which included $R$. amasae, $R$. sulphurea, $R$. quercus-mongolicae, $R$. quercivora, $R$. montetyi, and E. vermicola $(97,1$, and $89 \mathrm{ML}$ 


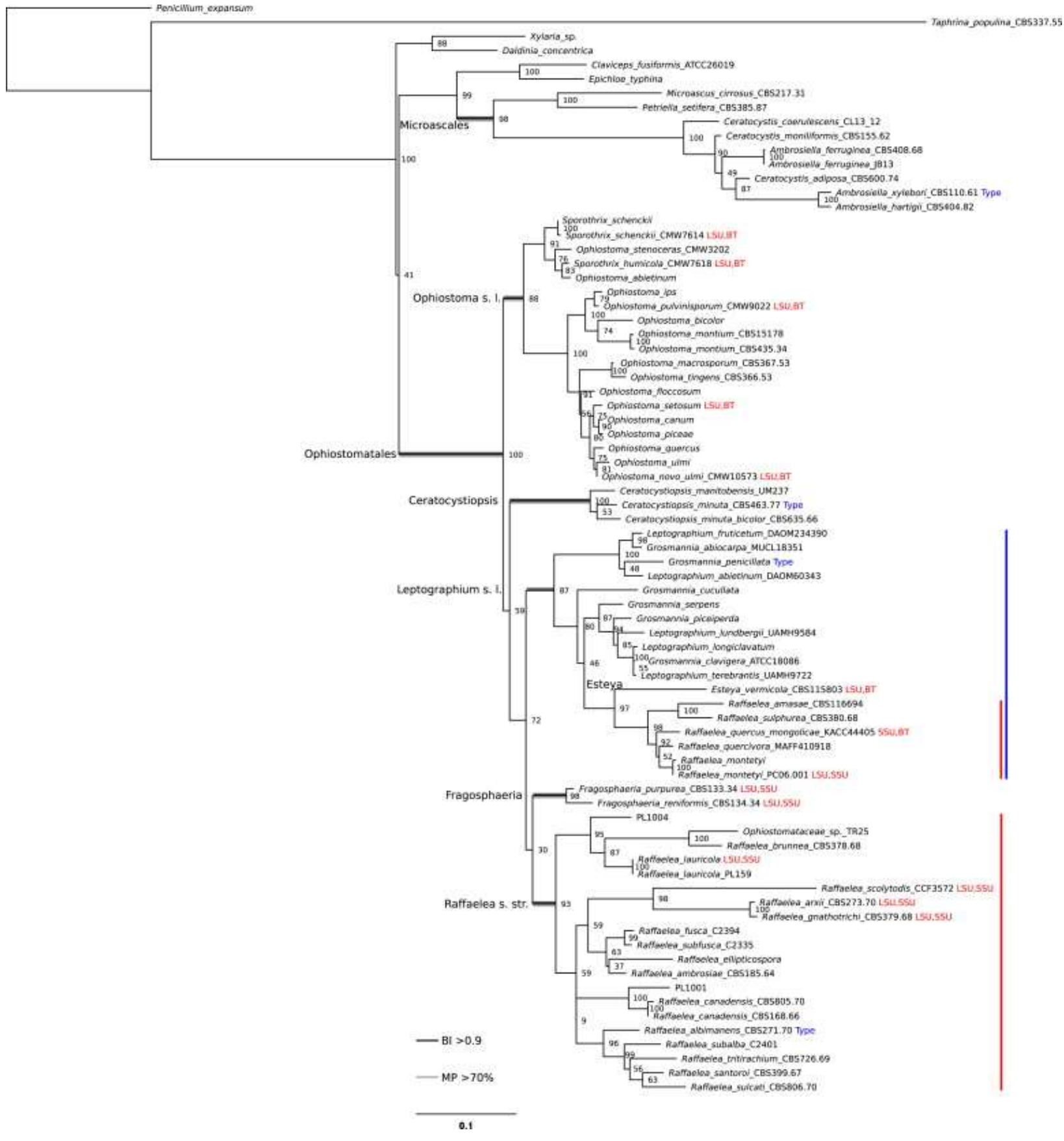

Fig 1. Raffaelea ML phylogeny from the combined, LSU, SSU, and BT dataset. Clade support values are ML bootstrap percentages with $\mathrm{BI}$ posterior probabilities $>0.9$ and MP bootstrap percentages $>70 \%$ for selected clades shown as bars above and below the branches, respectively. Type species for select genera are indicated in blue and isolates missing gene sequences have the genes that were used listed in red. Raffaelea isolates are highlighted with a red bars and Leptographium sensu lato with a blue bar. 
BS, BI PP, and MP BS values, respectively) within the Leptographium sensu lato clade (87, 1, 67, ML BS, BI PP, and MP BS values, respectively). The second Raffaelea clade contained $R$. brunnea, $R$. lauricola, $R$. scolytodis, $R$. arxii, $R$. gnathotrichi, $R$. fusca, R. subfusca, R. ellipticospora, R. ambrosiae (type species for the genus), $R$. canadensis, R. albimanens, R. subalba, R. tritirachium, R. santoroi, and R. sulcati (93, 1, and $87 \mathrm{ML} B S, \mathrm{BI} P P$, and MP BS values, respectively) and was sister to Leptographium sensu lato. The placement of Fragosphaeria was disregarded due to the incongruence of the different loci and the consequent uncertainty in its placement.

The log likelihood values from the ML unconstrained and the monophyletic Raffaelea constraint analyses were (-15790.81 and -15822.69$)$ and for the $\mathrm{BI}$ analyses were (-15943.84 and -15973.97 from Tracer) and (-15960.43 and -15997.19 from MrBayes), respectively. Although the ELW test indicated that the monophyletic constrained hypothesis was significantly worse than the unconstrained hypothesis (polyphyletic Raffaelea) (0.954 PP), the SH test did not find a significant difference between the hypotheses at alpha $<0.05$. The BFs were greater than 30 for both methods used, indicating very strong support for the polyphyletic Raffaelea hypothesis (Kass and Raftery 1995).

The ML analysis of the unidentified isolates provided evidence for six new taxa, and supported previous indications that isolate TR25 represented a distinct taxon (Massoumi Alamouti et al., 2009) (Fig 2). In the Leptographium sensu lato clade, isolate S28 was close to $R$. sulphurea, and isolates S31 and S32 were close to $R$. amasae. In the Raffaelea sensu stricto clade, S21 and S22 were close to PL1004 (see 
Dreaden et al. 2014 for more information on this isolate) and R. brunnea, PL1001 was near R. canadensis, and PL1635 was near R. scolytodis.

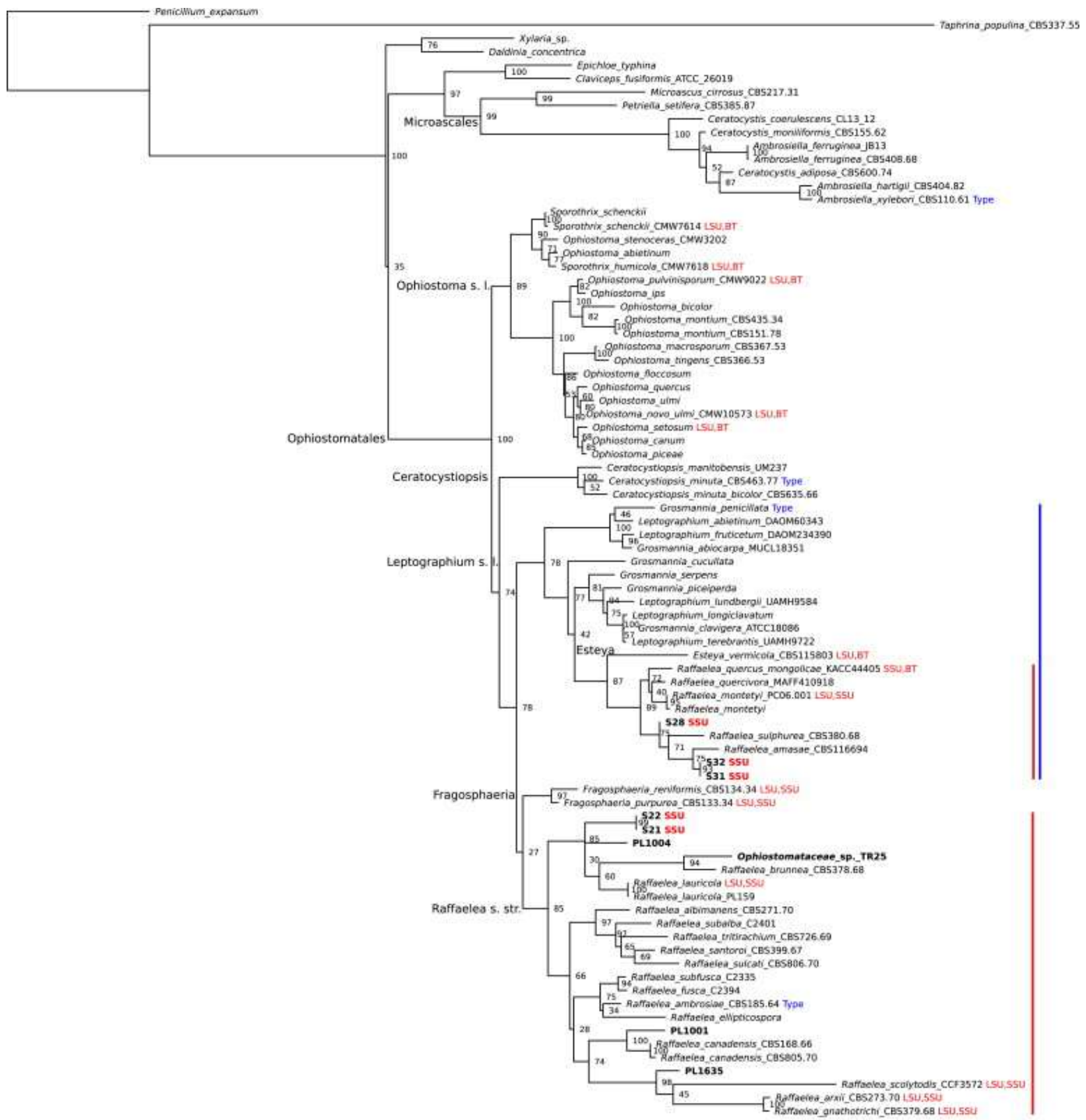

0.1

Fig 2. Raffaelea ML phylogeny with unidentified isolates, bold, from the combined, LSU, SSU, and BT dataset. Clade support values are ML bootstrap percentages. Notice there is support for 7 new taxa 1. S28, 2. S31 and S32, 3. S21 and S22, 4. PL1004, 5. Ophiostomataceae sp. TR25, 6. PL1001, and 7. PL1635. Type species for select genera are labeled in blue and isolates missing gene sequences have the genes that are available listed in red. Raffaelea isolates are highlighted with red bars and Leptographium sensu lato with a blue bar. 


\section{Discussion}

The $M L$ analyses of the individual gene datasets along with the $M L, B I$, and MP analyses of the combined dataset all indicated that Raffaelea, as it is currently defined, is polyphyletic. Esteya vermicola together with $R$. amasae, $R$. sulphurea, $R$. quercus-mongolicae, $R$. quercivora, and $R$. montetyi formed a strongly supported clade in Leptographium sensu lato (Fig 1, S2-S4). The remaining Raffaelea spp. resided in a second clade sister to Leptographium sensu lato, also with strong statistical support. Of the three tests used to consider monophyly in Raffaelea, only the $\mathrm{SH}$ test indicated that the constrained tree did not differ from the unconstrained tree. This is not surprising as the $\mathrm{SH}$ test has been shown to be conservative (Czarna et al. 2006, Shimodaira and Hasegawa 1999, Strimmer and Rambaut 2002). Taken as a whole, the evidence suggests that Raffaelea needs to be reevaluated and that Leptographium sensu lato should be included in this reevaluation.

This study recognizes $R$. brunnea, $R$. lauricola, $R$. scolytodis, $R$. arxii, $R$. gnathotrichi, $R$. fusca, $R$. subfusca, $R$. ellipticospora, $R$. ambrosiae, $R$. canadensis, R. albimanens, R. subalba, R. tritirachium, R. santoroi, and R. sulcati as Raffaelea sensu stricto. Raffaelea amasae, $R$. sulphurea, $R$. quercus-mongolicae, $R$. quercivora, and $R$. montetyi should be removed from Raffaelea, but their correct placement remains unclear at this time. Whether they should be placed in Leptographium sensu lato or accommodated in a reinstated Dryadomyces with $D$. amasae as the type species will require additional research. In particular, a phylogenetic study that includes all, or most, Leptographium sensu lato and Raffaelea taxa is recommended.

Massoumi Alamouti et al. (2009) noted, referencing work by Cassar and Blackwell (1996) and Farrell et al. (2001), that SSU-based phylogenies indicated that 
both Ambrosiella and Raffaelea are polyphyletic. This led these authors to suggest that the similar morphologies of the two genera and their intimate associations with ambrosia beetles arose more than once in each genus. The ambrosial habit in beetles is also polyphyletic and has arisen at least seven times (Farrell et al. 2001). The multiple origins of both ambrosial fungi, including Raffaelea, and the beetles with which they are associated suggests that these relationships should not be used to define Raffaelea.

The ML phylogenies of individual gene datasets and ML, BI, and MP phylogenies of the combined dataset in the present study show that Raffaelea is polyphyletic. This contradicts the MP results of Harrington et al. (2010) based on LSU data but is consistent with those based on the SSU data. These discrepancies could be due to differences in taxon sampling, the loci that were used, and the methodologies used to define these relationships (MP vs. ML). Although the effect of taxon sampling was not studied, the latter factors were shown to be significant, as a MP analysis of LSU data in the present study also placed Raffaelea spp. in a single clade (Fig S5). Thus, it appears that the previous conclusion (Harrington et al., 2010) that Raffaelea is monophyletic was an artifact of the MP analysis and LSU dataset that they used.

The $M L$ analyses suggest that the nine unidentified isolates included in this study contain seven undescribed taxa (Fig 2). These will be described elsewhere, as additional isolates become available. The results also provide a strong indication that there are many more new species of Raffaelea that remain to be identified. Clearly, care should be taken when new isolates of Raffaelea are identified and diagnostic and detection methods are designed. For example, isolate PL1004 had been identified as $R$. lauricola, based on SSU data, but was shown later to be non- 
pathogenic and is now considered to be a new species (Dreaden et al. 2014). Additionally, the $R$. lauricola detection method developed by Jeyaprakash et al. (2014) utilizes a portion of the LSU where PL1004 and R. lauricola have $100 \%$ sequence homology, implying that the method will likely detect PL1004 and $R$. lauricola equally well and thus resulting in false positives. Likewise, SSU data were used to identify isolate PL1001 as $R$. canadensis (Eskalen and McDonald 2011), which was shown in the present study to differ from that species. A more detailed study that includes additional isolates of the putative new taxa is needed to formally describe them as new species. The BS support for this analysis was lower for many clades when compared to the analysis not including the unknown isolates. This was probably due to the uncertain placement of the isolates from Grenada for which only SSU sequences were available (Fig 1 and 2).

The ITS region has been widely used for fungal diagnostics, phylogenetics and has been proposed as the universal DNA barcode marker for Fungi (Schoch et al. 2012). Unfortunately, the locus is notoriously difficult to utilize in Raffaelea (Harrington et al. 2011, Jeyaprakash et al. 2014). We were able to produce PCR amplicons, after much trial and error, for many Raffaelea spp. but only one high quality ITS sequence could be generated and this sequence along with those from GenBank could not be unambiguously aligned (Fig S1). Due to these difficulties, the ITS locus was not used to discern the phylogeny of Raffaelea spp. in this study. Jeyaprakash et al. (2014) were able to partially characterize the ITS for a $R$. lauricola isolate, after considerable modification to their sequencing methodology, and when aligned with the $R$. lauricola ITS2 sequence generated here has 15 bp differences, GenBank Accessions KJ909303 and KF515711 respectively. It would be interesting 
to sequence multiple cloned ITS PCR amplicons from multiple $R$. lauricola isolates to determine the prevalence of intraspecific and intragenomic ITS variants.

\section{Acknowledgements}

Funding for this project was provided by the United States Department of Agriculture AFRI Biosecurity Program Project Number 2010-85605-20537 and NIFA grant 2009-51181-05915. We thank Dr. Tom Harrington, Dr. Akif Eskalen, and Craig Bateman for providing isolates and Adam Black, Dr. Robert Blanchette, Dr. Tuan Duong, members of the University of Florida Forest Pathology Laboratory and the University of Pretoria Forestry and Agricultural Biotechnology Institute for their assistance.

\section{LIST OF REFERENCES}

Arx JA von, Hennebert GL, 1965. Deux champignons ambrosia. Mycopathologia et Mycologia Applicata 25: 309-315.

Batra LR. 1967. Ambrosia fungi: a taxonomic revision and nutritional status of some species. Mycologia 59: 979-1017.

Cassar S, Blackwell M, 1996. Convergent origins of ambrosia fungi. Mycologia 88: 596-601.

Czarna A, Sanjuán R, González-Candelas F, Wróbel B, 2006. Topology testing of phylogenies using least squares methods. BMC Evolutionary Biology 6: 105.

De Beer ZW, Seifert KA, Wingfield MJ 2013a. The ophiostomatoid fungi: their dual position in the Sordariomycetes. In: Seifert KA, De Beer ZW, Wingfield MJ, (eds), The Ophiostomatoid Fungi: Expanding Frontiers CBS Biodiversity Series Vol. 12, CBS-KNAW Fungal Biodiversity Centre, Utrecht, The Netherlands: pp. 1-19.

De Beer ZW, Seifert KA, Wingfield MJ 2013b. A nomenclator for ophiostomatoid genera and species in the Ophiostomatales and Microascales. In: Seifert KA, De Beer ZW, Wingfield MJ, (eds), The Ophiostomatoid Fungi: Expanding Frontiers CBS Biodiversity Series Vol. 12, CBS-KNAW Fungal Biodiversity Centre, Utrecht, The Netherlands: pp. 245-322.

De Beer ZW, Wingfield MJ 2013. Emerging lineages in the Ophiostomatales. In: Seifert KA, De Beer ZW, Wingfield MJ, (eds), The Ophiostomatoid Fungi: 
Expanding Frontiers CBS Biodiversity Series Vol. 12, CBS-KNAW Fungal Biodiversity Centre, Utrecht, The Netherlands: pp. 21-46.

Dreaden TJ, Davis JM, Harmon CL, Ploetz RC, Palmateer AJ, Soltis PS, Smith JA, 2014. Development of multilocus PCR assays for Raffaelea lauricola, causal agent of laurel wilt disease. Plant Disease 98: 379-383.

Duong TA, de Beer ZW, Wingfield BD, Wingfield MJ, 2012. Phylogeny and taxonomy of species in the Grosmannia serpens complex. Mycologia 104: 715-732, doi:10.3852/11-109.

Eskalen A, McDonald V, 2011. First Report of Raffaelea canadensis Causing Laurel Wilt Disease Symptoms on Avocado in California. Plant Disease 95: 9-1189.

Farrell BD, Sequeira ASO, Meara BC, Normark BB, Chung JH, Jordal BH, 2001. The evolution of agriculture in beetles (Curculionidae: Scolytinae and Platypodinae). Evolution 55: 2011-2027.

Gardes M, Bruns TD, 1993. ITS primers with enhanced specificity for basidiomycetes - application to the identification of mycorrhizae and rusts. Molecular Ecology 2: 113-118.

Gebhardt H, Oberwinkler F, 2005. Conidial development in selected ambrosial species of the genus Raffaelea. Antonie von Leeuwenhoek 88: 61-66.

Gebhardt H, Weiss M, Oberwinkler F, 2005. Dryadomyces amasae: a nutritional fungus associated with ambrosia beetles of the genus Amasa (Coleoptera: Curculionidae, Scolytinae). Mycological Research 109: 687-696.

Glass NL, Donaldson GC, 1995. Development of primer sets designed for use with the PCR to amplify conserved genes from filamentous ascomycetes. Applied and Environmental Microbiology 61: 1323-1330.

Harrington TC, Yun HY, Lu SS, Goto H, Aghayeva DN, Fraedrich SW, 2011. Isolations from the redbay ambrosia beetle, Xyleborus glabratus, confirm that the laurel wilt pathogen, Raffaelea lauricola, originated in Asia. Mycologia 103: 1028-1036.

Harrington TC, Aghayeva DN, Fraedrich SW, 2010. New combinations in Raffaelea, Ambrosiella, and Hyalorhinocladiella, and four new species from the redbay ambrosia beetle, Xyleborus glabratus. Mycotaxon 111: 337-361.

Harrington TC, Fraedrich SW, Aghayeva DN, 2008. Raffaelea lauricola, a new ambrosia beetle symbiont and pathogen on the Lauraceae. Mycotaxon 104: 399-404.

Hipp AL, Hall JC, Sytsma KJ, 2004. Congruence Versus Phylogenetic Accuracy: Revisiting the Incongruence Length Difference Test. Systematic Biology 53: 81-89.

James TY, Kauff F, Schoch CL, Matheny PB, Hofstetter V, Cox CJ, Celio G, Gueidan C, Fraker E, Miadlikowska J (70 co-authors), 2006. Reconstructing 
the early evolution of Fungi using a six-gene phylogeny. Nature 443: 818822.

Jeyaprakash A, Davison DA, Schubert TS, 2014. Molecular Detection of the Laurel Wilt Fungus, Raffaelea lauricola. Plant Disease 98: 559-654.

Jones KG, Blackwell M. 1998. Phylogenetic analysis of ambrosial species in the genus Raffaelea based on 18S rDNA sequences. Mycological Research 102: 661-665.

Justesen AF, Ridout CJ, Hovmoller MS, 2002. The recent history of Puccinia striiformis f.sp. tritici in Denmark as revealed by disease incidence and AFLP markers. Plant Pathology 51: 13-23.

Kass RE, Raftery AE, 1995. Bayes factors. Journal of the American Statistical Association 90: 773-795.

Kim KH, Choi YJ, Seo ST, Shin HD, 2009. Raffaelea quercus-mongolicae sp. nov. associated with Platypus koryoensis on oak in Korea. Mycotaxon 110: 189 197.

Kubono T, Ito S, 2002. Raffaelea quercivora sp. Novo associated with mass mortality of Japanese oak, and the ambrosia beetle (Platypus quercivorus). Mycoscience 43: 255-260.

Massoumi Alamouti S, Tsui CKM, Breuil C, 2009. Multigene phylogeny of filamentous ambrosia fungi associated with ambrosia and bark beetles. Mycological Research 113: 822-835.

O'Donnell K. 1993. Fusarium and its near relatives. In: Reynolds R. Taylor JW, (eds), The fungal holomorph: mitotic, meiotic and pleomorphic speciation in fungal systematics. Wallingford, United Kingdom: CBA International. pp 225-233.

Ploetz RC, Hulcr J, Wingfield MJ, de Beer ZW, 2013. Destructive Tree Diseases Associated with Ambrosia and Bark Beetles: Black Swan Events in Tree Pathology? Plant Disease 97: 856-872.

Ploetz RC, Pena JE, Smith JA, Dreaden TJ, Crane JH, Schubert T, Dixon W, 2011. Laurel Wilt, Caused by Raffaelea lauricola, is Confirmed in Miami-Dade County, Center of Florida's Commercial Avocado Production. Plant Disease 95: 1589.

Posada D, 2008. jModelTest: phylogenetic model averaging. Molecular Biology and Evolution 25: 1253-1256.

Rambaut A, Drummond AJ, 2007. Tracer 1.4. Available at http://beast.bio.ed.ac.uk/Tracer

Ronquist F, Teslenko M, van der Mark P, Ayres D, Darling A, Höhna S, Larget B, Liu L, Suchard MA, Huelsenbeck JP, 2012. MrBayes 3.2: efficient Bayesian phylogenetic inference and model choice across a large model space. Systematic Biology 61: 539-542. 
Schoch CL, Seifert KA, Huhndorf S, Robert V, Spouge JL, Levesque A, Chen W, Fungal Barcode Consortium, 2012. Nuclear ribosomal internal transcribed spacer (ITS) region as a universal DNA barcode marker for Fungi.

Proceedings of the National Academy of Sciences of the United States of America 109: 6241-6246, doi:10.1073/pnas.1117018109

Shimodaira H, Hasegawa M, 1999. Multiple comparisons of log-likelihoods with applications to phylogenetic inference. Molecular Biology Evolution 16: 11141116.

Slippers B, Boissin E, Phillips AJ, Groenewald JZ, Lombard L, Wingfield MJ, Postma A, Burgess T, Crous PW, 2013. Phylogenetic lineages in the Botryosphaeriales: a systematic and evolutionary framework. Studies in Mycology 76: 31-49, doi: 10.3114/sim0020

Stamatakis A, 2006. RAxML-VI-HPC: Maximum Likelihood-based Phylogenetic Analyses with Thousands of Taxa and Mixed Models. Bioinformatics 22: 2688-2690.

Strimmer K, Rambaut A, 2002. Inferring confidence sets of possibly misspecified gene trees. Proceedings of the Royal Society London Biological Sciences 269: $137-142$.

Swofford DL, 2003. PAUP* 4.0: phylogenetic analysis using parsimony ("and other methods). Sunderland, Massachusetts: Sinauer Associates.

Vilgalys R, Hester M, 1990. Rapid genetic identification and mapping of enzymatically amplified ribosomal DNA from several Cryptococcus species. Journal of Bacteriology 172: 4238-4246.

Wingfield BD, Van Wyk M, Roos $\mathrm{H}$, Wingfield MJ 2013. Ceratocystis: emerging evidence for discrete generic boundaries. In: Seifert KA, De Beer ZW, Wingfield MJ, (eds), The Ophiostomatoid Fungi: Expanding Frontiers CBS Biodiversity Series Vol. 12, CBS-KNAW Fungal Biodiversity Centre, Utrecht, The Netherlands: pp. 57-64.

White TJ, Bruns T, Lee S, Taylor J, 1990. Amplification and direct sequencing of fungal ribosomal RNA genes for phylogenetics. In: Inis MA, Gelfand DH, Sninsky JJ, White TJ, (eds), PCR protocols: a guide to methods and applications. San Diego: Academic Press pp. 315-322. 


\section{Supplementary data}

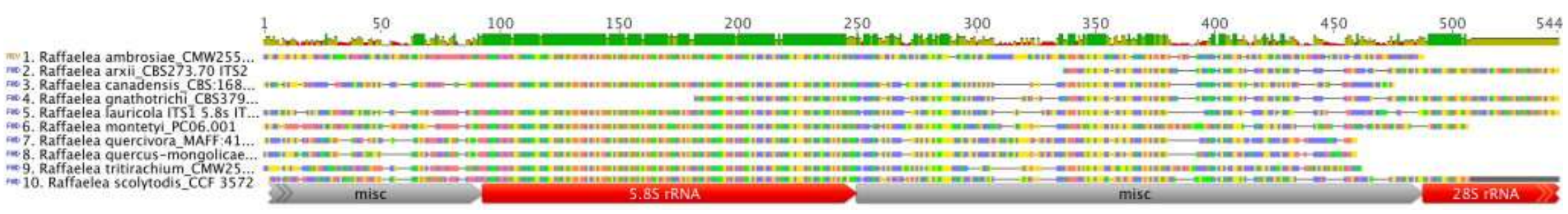

Fig S1. Alignment of the rDNA internal transcribed spacer region, ITS, from 10 Raffaelea species. Note that only the $5.8 \mathrm{~s}$ and portions of the $28 \mathrm{~s}$ LSU could be aligned unambiguously. The bar graph at the top of the figure indicates the degree of similarity among sequences. 


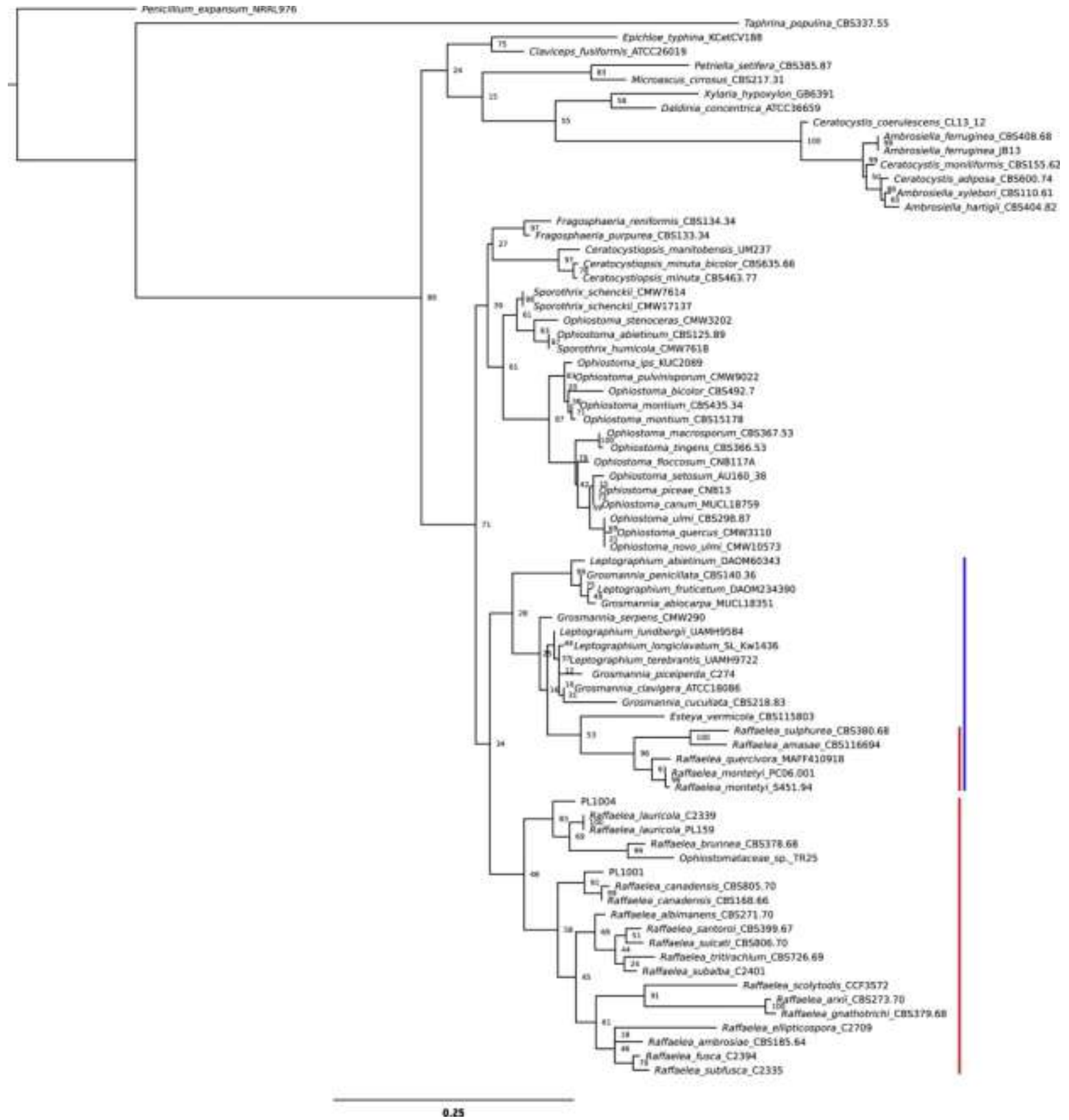

Fig S2. LSU-based phylogeny of Raffaelea and related taxa. The bipartition tree from the RAxML maximum likelihood analysis with 1000 bootstrap replicates is shown. Raffaelea isolates are highlighted with red bars and Leptographium sensu lato with a blue bar to aid comparisons of the individual gene phylogenies (Fig S2-S4). 


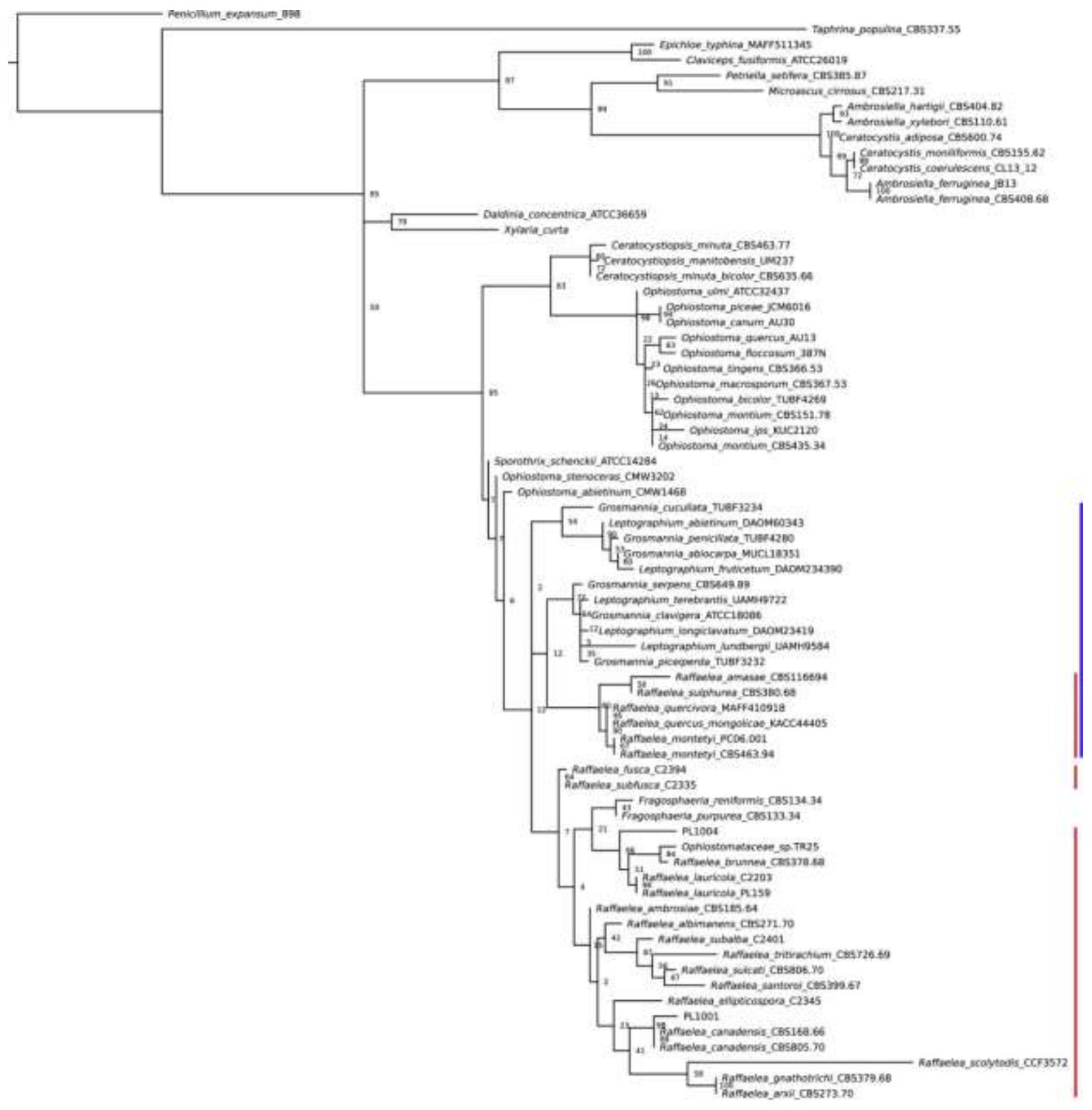

0.25

Fig S3. SSU-based phylogeny of Raffaelea and related taxa. The bipartition tree from the RAxML maximum likelihood analysis with 1000 bootstrap replicates is shown. Raffaelea isolates are highlighted with red bars and Leptographium sensu lato with a blue bar to aid comparisons of the individual gene phylogenies (Fig S2-S4). 


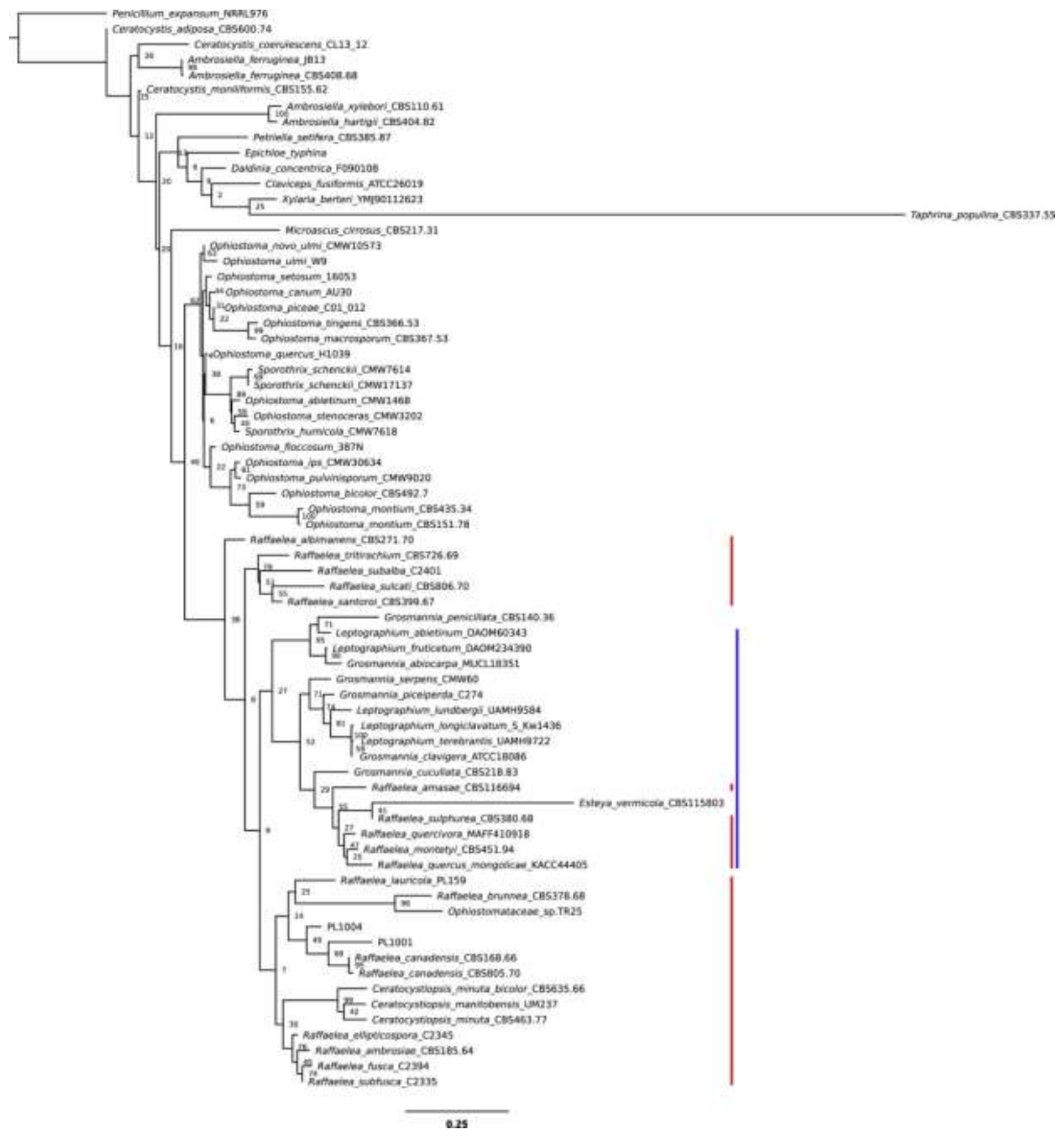

Fig S4. BT-based phylogeny of Raffaelea and related taxa. The bipartition tree from the RAxML maximum likelihood analysis with 1000 bootstrap replicates is shown. Raffaelea isolates are highlighted with red bars and Leptographium sensu lato with a blue bar to aid comparisons of the individual gene phylogenies (Fig S2-S4). 


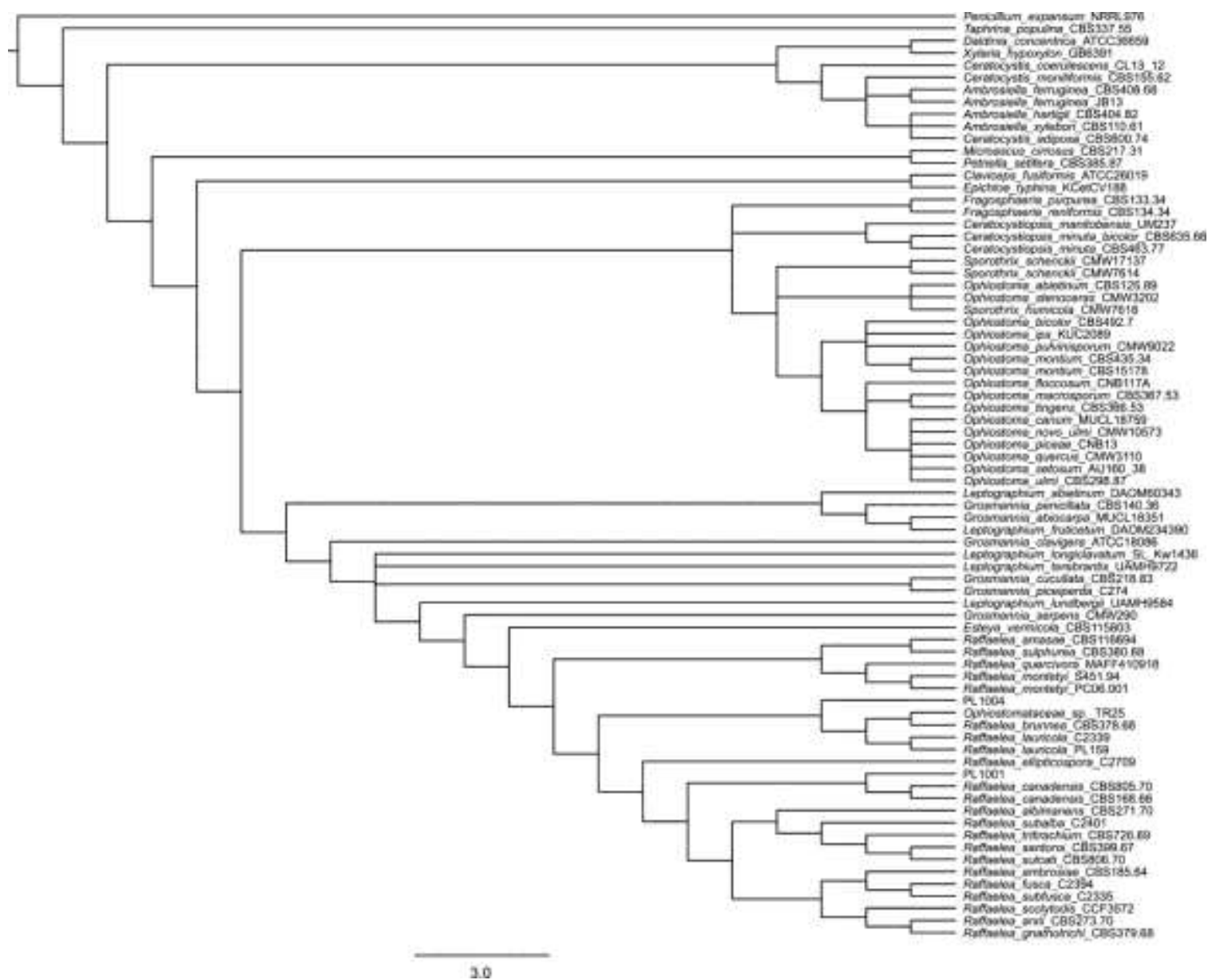

Fig S5. Strict consensus of 20,700 most parsimonious trees using the LSU dataset and PAUP* (465 total characters, 230 were constant, and 195 were parsomony-informative). Gaps were treated as missing data, and the TBR branch swapping algorithm was used (Swofford 2003). This LSU MP analysis found Raffaelea as defined by Harrington et al. (2010) to be monophyletic, as did their LSU MP analysis. Where as, the ML (LSU, SSU and BT) analyses (Fig S2-S4) as well as the ML, BI and MP analyses using the combined data sets, in this study, found Raffaelea spp. in both the Raffaelea and the Leptographium sensu lato clades (Fig 1). These findings provide evidence the cause of the incongruence between our findings that Raffealea is not monophyletic, and the Harrington et al. (2010) LSU MP study is because of an interaction between the LSU dataset and MP. 